\title{
Front Matter: Volume 7863
}

, "Front Matter: Volume 7863," Proc. SPIE 7863, Stereoscopic Displays and Applications XXII, 786301 (22 March 2011); doi: 10.1117/12.891041

Event: IS\&T/SPIE Electronic Imaging, 2011, San Francisco Airport, California, United States 


\title{
PROCEEDINGS \\ IS\&T/SPIE \\ Electronic \\ meging \\ Science and Technology
}

\section{Stereoscopic Displays and Applications XXII}

\author{
Andrew J. Woods \\ Nicolas S. Holliman \\ Neil A. Dodgson \\ Editors
}

24-27 January 2011

San Francisco, California, United States

Sponsored and Published by

IS\&T-The Society for Imaging Science and Technology

SPIE

Cosponsored by

IMAX Corporation (Canada)

DepthQ Stereoscopic (United States) 
The papers included in this volume were part of the technical conference cited on the cover and title page. Papers were selected and subject to review by the editors and conference program committee. Some conference presentations may not be available for publication. The papers published in these proceedings reflect the work and thoughts of the authors and are published herein as submitted. The publishers are not responsible for the validity of the information or for any outcomes resulting from reliance thereon.

Please use the following format to cite material from this book:

Author(s), "Title of Paper," in Stereoscopic Displays and Applications XXII, edited by Andrew J. Woods, Nicolas S. Holliman, Neil A. Dodgson, Proceedings of SPIE-IS\&T Electronic Imaging, SPIE Vol. 7863, Article CID Number (2011).

ISSN 0277-786X

ISBN 9780819484000

Copublished by

SPIE

P.O. Box 10, Bellingham, Washington 98227-0010 USA

Telephone +1 3606763290 (Pacific Time) · Fax +1 3606471445

SPIE.org

and

IS\&T-The Society for Imaging Science and Technology

7003 Kilworth Lane, Springfield, Virginia, 22151 USA

Telephone +1 7036429090 (Eastern Time) · Fax +1 7036429094

imaging.org

Copyright (C) 2011, Society of Photo-Optical Instrumentation Engineers and The Society for Imaging Science and Technology.

Copying of material in this book for internal or personal use, or for the internal or personal use of specific clients, beyond the fair use provisions granted by the U.S. Copyright Law is authorized by the publishers subject to payment of copying fees. The Transactional Reporting Service base fee for this volume is $\$ 18.00$ per article (or portion thereof), which should be paid directly to the Copyright Clearance Center (CCC), 222 Rosewood Drive, Danvers, MA 01923. Payment may also be made electronically through CCC Online at copyright.com. Other copying for republication, resale, advertising or promotion, or any form of systematic or multiple reproduction of any material in this book is prohibited except with permission in writing from the publisher. The CCC fee code is $0277-786 \mathrm{X} / 11 / \$ 18.00$.

Printed in the United States of America.

Paper Numbering: Proceedings of SPIE follow an e-First publication model, with papers published first online and then in print and on CD-ROM. Papers are published as they are submitted and meet publication criteria. A unique, consistent, permanent citation identifier (CID) number is assigned to each article at the time of the first publication. Utilization of CIDs allows articles to be fully citable as soon as they are published online, and connects the same identifier to all online, print, and electronic versions of the publication. SPIE uses a six-digit CID article numbering system in which:

- The first four digits correspond to the SPIE volume number.

- The last two digits indicate publication order within the volume using a Base 36 numbering system employing both numerals and letters. These two-number sets start with 00, 01, 02, 03, 04, 05, 06, 07 , 08, 09, OA, OB ... OZ, followed by 10-1Z, 20-2Z, etc.

The CID number appears on each page of the manuscript. The complete citation is used on the first page, and an abbreviated version on subsequent pages. Numbers in the index correspond to the last two digits of the six-digit CID number. 


\title{
Contents
}

\author{
xi Conference Committee \\ xiii Introduction
}

\section{VISUAL COMFORT AND QUALITY}

786302 Adapting stereoscopic movies to the viewing conditions using depth-preserving and artifact-free novel view synthesis [7863-01]

F. Devernay, S. Duchêne, A. Ramos-Peon, INRIA Grenoble - Rhône-Alpes (France)

786303 Visual fatigue monitoring system based on eye-movement and eye-blink detection [7863-02]

D. Kim, S. Choi, J. Choi, H. Shin, K. Sohn, Yonsei Univ. (Korea, Republic of)

786304 Factors impacting quality of experience in stereoscopic images [7863-03]

L. Xing, J. You, Norwegian Univ. of Science and Technology (Norway); T. Ebrahimi, Norwegian Univ. of Science and Technology (Norway) and Ecole Polytechnique Fédérale de Lausanne (Switzerland); A. Perkis, Norwegian Univ. of Science and Technology (Norway)

786305 Visual discomfort induced by fast salient object motion in stereoscopic video [7863-04] S. Lee, Y. J. Jung, H. Sohn, Y. M. Ro, H. W. Park, Korea Advanced Institute of Science and Technology (Korea, Republic of)

786306 3D video disparity scaling for preference and prevention of discomfort [7863-05] H. Pan, C. Yuan, S. Daly, Sharp Labs. of America, Inc. (United States)

\section{COMBINING DEPTH CUES}

786307 Can the perception of depth in stereoscopic images be influenced by 3D sound? [7863-06] A. Turner, J. Berry, N. Holliman, Durham Univ. (United Kingdom)

786308 Evaluating motion and binocular parallax as depth cues for autostereoscopic displays [7863-07]

M. Braun, Hochschule für Technik und Wirtschaft Berlin (Germany); U. Leiner, D. Ruschin, Fraunhofer-Institut für Nachrichtentechnik Heinrich-Hertz-Institut (Germany)

\section{VIEW SYNTHESIS}

7863 OA A multi-resolution multi-size-windows disparity estimation approach [7863-09] J. Martinez Bauza, Qualcomm Inc. (United States); M. Shiralkar, Clemson Univ. (United States)

7863 OB Warping error analysis and reduction for depth-image-based rendering in 3DTV [7863-10] L. Do, S. Zinger, Eindhoven Univ. of Technology (Netherlands); P. H. N. de With, Eindhoven Univ. of Technology (Netherlands) and Cyclomedia Technology B.V. (Netherlands) 
7863 OC Novel view synthesis for dynamic scene using moving multi-camera array [7863-11] T. Yokoi, Nagoya Univ. (Japan); N. Fukushima, Nagoya Institute of Technology (Japan); T. Yendo, M. Panahpour Tehrani, Nagoya Univ. (Japan); T. Fujii, Tokyo Institute of Technology (Japan); M. Tanimoto, Nagoya Univ. (Japan)

7863 OD Depth-based representations: Which coding format for 3D video broadcast applications? [7863-12]

P. Kerbiriou, G. Boisson, K. Sidibé, Q. Huynh-Thu, Technicolor R\&D France (France)

\section{MULTIVIEW SYSTEMS}

7863 OE Multiview image compression based on a new basis representation [7863-13]

T. Yamada, T. Fujii, Tokyo Institute of Technology (Japan)

7863 OF Design of tuneable anti-aliasing filters for multiview displays [7863-14]

A. Boev, R. Bregovic, A. Gotchev, Tampere Univ. of Technology (Finland)

7863 OG Multiview image compression based on LDV scheme [7863-15]

B. Battin, C. Niquin, P. Vautrot, Univ. de Reims Champagne-Ardenne (France); D. Debons, 3DTV Solutions (France); L. Lucas, Univ. de Reims Champagne-Ardenne (France) and 3DTV Solutions (France)

$7863 \mathrm{OH} \quad$ Upsampling range camera depth maps using high-resolution vision camera and pixel-level confidence classification [7863-16]

C. Tian, V. Vaishampayan, AT\&T Labs. Research (United States); Y. Zhang, Texas A\&M Univ. (United States)

\section{APPLICATIONS OF STEREOSCOPIC DISPLAYS}

7863 ol Attack! of the S. Mutans: a stereoscopic-3D multiplayer direct-manipulation behaviormodification serious game for improving oral health in pre-teens [7863-17] A. Hollander, H. Rose, J. Kollin, W. Moss, Firsthand Technology Inc. (United States)

$78630 \mathrm{~J}$ Stereoscopic multi-perspective capture and display in the performing art [7863-18] V. Kuchelmeister, The Univ. of New South Wales (Australia)

7863 OK Machine vision and vitrectomy: three-dimensional high definition (3DHD) video for surgical visualization in vitreoretinal surgery [7863-19]

C. D. Riemann, Cincinnati Eye Institute (United States)

\section{STEREOSCOPIC DISPLAY DEVELOPMENTS}

$7863 \mathrm{OL} \quad$ High image quality 3D displays with polarizer glasses based on active retarder technology [7863-20]

S. Jung, Y. Lee, H. Park, J. Park, D. Lee, W. Jeong, J. Kim, I.-J. Chung, LG Display Co. Ltd.

(Korea, Republic of)

7863 OM High brightness film projection system [7863-21]

L. Lipton, Oculus3D (United States) 
786300 Continuously adjustable Pulfrich spectacles [7863-23]

K. Jacobs, Binghamton Univ. (United States); R. Karpf, ADDIS Inc. (United States)

EVALUATING THE QUALITY OF THE STEREOSCOPIC EXPERIENCE I: JOINT SESSION WITH CONFERENCE 7865

7863 OP Visual discomfort with stereo displays: effects of viewing distance and direction of vergence-accommodation conflict [7863-24]

T. Shibata, Univ. of California, Berkeley (United States) and Waseda Univ. (Japan); J. Kim,

D. M. Hoffman, M. S. Banks, Univ. of California, Berkeley (United States)

$78630 Q$ Effects of vergence and accommodative responses on viewer's comfort in viewing 3D stimuli [7863-66]

S.-N. Yang, J. E. Sheedy, Pacific Univ. (United States)

EVALUATING THE QUALITY OF THE STEREOSCOPIC EXPERIENCE II: JOINT SESSION WITH CONFERENCE 7865

7863 OR Effect of image scaling on stereoscopic movie experience [7863-25]

J. Häkkinen, J. Hakala, Aalto Univ. School of Science and Technology (Finland);

M. Hannuksela, Nokia Research Ctr. (Finland); P. Oittinen, Aalto Univ. School of Science and Technology (Finland)

7863 OS Relationship between perception of image resolution and peripheral visual field in stereoscopic images [7863-26]

M. Ogawa, K. Shidoji, Kyushu Univ. (Japan)

\section{AUTOSTEREOSCOPIC DISPLAYS I}

7863 От Implementation of autostereoscopic HD projection display with dense horizontal parallax [7863-27]

S. Iwasawa, M. Kawakita, National Institute of Information and Communications Technology (Japan); S. Yano, NHK Science \& Technical Research Labs. (Japan); H. Ando, National Institute of Information and Communications Technology (Japan)

7863 OU Full-parallax 360 degrees horizontal viewing integral imaging using anamorphic optics [7863-28]

M.-U. Erdenebat, G. Baasantseren, J.-H. Park, N. Kim, K.-C. Kwon, Y.-H. Jang, K.-H. Yoo,

Chungbuk National Univ. (Korea, Republic of)

7863 OV Optical characterization of autostereoscopic 3D displays [7863-29]

M. Sykora, J. Schultz, R. Brott, 3M Co. (United States)

\section{AUTOSTEREOSCOPIC DISPLAYS II}

7863 OW Depth cube display using depth map [7863-30]

J.-H. Jung, B.-S. Song, S.-W. Min, Kyung Hee Univ. (Korea, Republic of) 
7863 OX Surface representation of 3D object for aerial 3D display [7863-31]

H. Ishikawa, H. Watanabe, S. Aoki, H. Saito, Keio Univ. (Japan); S. Shimada, M. Kakehata,

Y. Tsukada, National Institute of Advanced Industrial Science and Technology (Japan);

H. Kimura, Aerial Systems Inc. (Japan) and Burton Inc. (Japan)

\section{CROSSTALK IN STEREOSCOPIC DISPLAYS}

$7863 \mathrm{OZ} \quad$ How are crosstalk and ghosting defined in the stereoscopic literature? [7863-33]

A. J. Woods, Curtin Univ. (Australia)

786310 A simple method for measuring crosstalk in stereoscopic displays [7863-34]

M. A. Weissman, TrueVision Systems, Inc. (United States); A. J. Woods, Curtin Univ. (Australia)

786311 Ergonomic evaluation of crosstalk in stereoscopy through heart activity and forehead blood flow [7863-35]

S. Toyosawa, Waseda Univ. (Japan) and Tokuyama Univ. (Japan); H. Morikawa, K. Nakano, T. Kawai, Waseda Univ. (Japan); C.-S. Chen, H.-L. Chang, J.-C. Yang, Industrial Technology Research Institute (Taiwan)

786312 Optical characterization of shutter glasses stereoscopic 3D displays [7863-36]

P. Boher, T. Leroux, V. Collomb Patton, T. Bignon, ELDIM (France)

786313 The effect of crosstalk on depth magnitude in thin structures [7863-37]

I. Tsirlin, L. M. Wilcox, R. S. Allison, York Univ. (Canada)

\section{D PERCEPTION AND INTERACTION}

786314 Effects of stereoscopic presentation on visually induced motion sickness [7863-38]

H. Ujike, H. Watanabe, National Institute of Advanced Industrial Science and Technology (Japan)

786315 Vergence and accommodation to multiple-image-plane stereoscopic displays: 'Real world' responses with practical image-plane separations? [7863-39]

K. J. MacKenzie, R. A. Dickson, S. J. Watt, Bangor Univ. (United Kingdom)

$786316 \quad$ Evaluating stereoscopic displays: both efficiency measures and perceived workload sensitive to manipulations in binocular disparity [7863-40]

M. H. P. H. van Beurden, W. A. ljsselsteijn, Y. A. W. de Kort, Eindhoven Univ. of Technology (Netherlands)

786317 Comparison of relative (mouse-like) and absolute (tablet-like) interaction with a large stereoscopic workspace [7863-41]

M. Averkiou, N. A. Dodgson, Univ. of Cambridge (United Kingdom)

\section{D CONTENT}

786318 Optimal design and critical analysis of a high resolution video plenoptic demonstrator [7863-42]

V. Drazic, J.-J. Sacré, J. Bertrand, A. Schubert, E. Blondé, Technicolor S.A. (France) 
786319 Geometric and subjective analysis of stereoscopic I3A cluster images [7863-43]

M. Kytö, J. Hakala, Aalto Univ. School of Science and Technology (Finland)

STEREOSCOPIC PRODUCTION AND PLAYBACK

78631 1A The Dynamic Floating Window: a new creative tool for 3D movies [7863-44]

B. R. Gardner, Independent Stereographer and 3D Consultant (United States)

7863 1B Stereo video inpainting [7863-45]

F. Raimbault, A. Kokaram, Trinity College Dublin (Ireland)

7863 1C A modified non-local mean inpainting technique for occlusion filling in depth-image-based rendering [7863-46]

L. Azzari, Tampere Univ. of Technology (Finland); F. Battisti, Univ. degli Studi di Roma Tre (Italy); A. Gotchev, Tampere Univ. of Technology (Finland); M. Carli, Univ. degli Studi di Roma Tre (Italy); K. Egiazarian, Tampere Univ. of Technology (Finland)

7863 1D A study on the stereoscopic codecs for non-real-time 3DTV services [7863-47]

B. Lee, Electronics and Telecommunications Research Institute (Korea, Republic of);

B.-T. Lee, Korea Aerospace Univ. (Korea, Republic of); W.-S. Cheong, N. Hur, S. Lee, Electronics and Telecommunications Research Institute (Korea, Republic of); J.-G. Kim, Korea Aerospace Univ. (Korea, Republic of)

7863 IE A modular cross-platform GPU-based approach for flexible 3D video playback [7863-48] R. Olsson, H. Andersson, M. Sjöström, Mid Sweden Univ. (Sweden)

INTERACTIVE PAPER SESSION

7863 IF Human perception considerations for 3D content creation [7863-49]

G. A. Green, Almont Green Studios (United States)

$78631 \mathrm{H} \quad$ Automatic 3D video format detection [7863-51]

T. Zhang, Z. Wang, J. Zhai, Technicolor (United States); D. Doyen, Technicolor S.A. (France)

$786311 \quad$ Low-complexity 2D to 3D video conversion [7863-52]

Y. Chen, R. Zhang, M. Karczewicz, Qualcomm Inc. (United States)

$78631 \mathrm{~J}$ Development of a modular stereoscopic pre-visualisation and display framework [7863-53]

V. Kuchelmeister, The Univ. of New South Wales (Australia)

$78631 \mathrm{~K}$ Color appearance in stereoscopy [7863-54]

D. Gadia, A. Rizzi, C. Bonanomi, D. Marini, Univ. degli Studi di Milano (Italy); A. Galmonte, Univ. degli Studi di Verona (Italy); T. Agostini, Univ. degli Studi di Trieste (Italy)

$78631 \mathrm{~L}$ Coarse integral volumetric imaging with flat screen and wide viewing angle [7863-55]

S. Sawada, H. Kakeya, Univ. of Tsukuba (Japan)

$78631 \mathrm{M}$ Coarse integral imaging without pseudo image [7863-56]

T. Kurokawa, H. Kakeya, Univ. of Tsukuba (Japan) 
7863 iN Free-viewpoint image generation from a video captured by a handheld camera [7863-57] K. Takeuchi, Nagoya Univ. (Japan); N. Fukushima, Nagoya Institute of Technology (Japan); T. Yendo, M. Panahpour Tehrani, Nagoya Univ. (Japan); T. Fujii, Tokyo Institute of Technology (Japan); M. Tanimoto, Nagoya Univ. (Japan)

786310 New stereoscopic video shooting rule based on stereoscopic distortion parameters and comfortable viewing zone [7863-58]

W. Chen, France Télécom (France) and Institut de Recherche en Communications et Cybernétique de Nantes, CNRS, Univ. de Nantes (France); J. Fournier, France Télécom (France); M. Barkowsky, P. Le Callet, Institut de Recherche en Communications et Cybernétique de Nantes, CNRS, Univ. de Nantes (France)

7863 1P Reduced-view super multi-view display [7863-59]

J. Nakamura, K. Tanaka, Tokyo Univ. of Agriculture and Technology (Japan); C.-H. Tsai, Industrial Technology Research Institute (Taiwan); Y. Takaki, Tokyo Univ. of Agriculture and Technology (Japan)

$78631 Q \quad$ Psycho-physiological effects of visual artifacts by stereoscopic display systems [7863-60] S. Kim, J. Yoshitake, H. Morikawa, T. Kawai, O. Yamada, Waseda Univ. (Japan); A. Iguchi, ASTRODESIGN, Inc. (Japan)

$78631 R \quad$ 2D viewing experience with fixed 3D displays [7863-62]

M. Salmimaa, T. Järvenpää, M. Pölönen, Nokia Research Ctr. (Finland)

7863 is Interestingness of stereoscopic images [7863-63]

J. Hakala, M. Nuutinen, P. Oittinen, Aalto Univ. (Finland)

7863 1T Subjective evaluation of HDTV stereoscopic videos in IPTV scenarios using absolute category rating [7863-64]

K. Wang, Acreo AB (Sweden) and Mid Sweden Univ. (Sweden); M. Barkowsky, R. Cousseau, Institut de Recherche en Communications et Cybernétique de Nantes, CNRS, Univ. de Nantes (France); K. Brunnström, Acreo AB (Sweden); R. Olsson, Mid Sweden Univ. (Sweden); P. Le Callet, Institut de Recherche en Communications et Cybernétique de Nantes, CNRS, Univ. de Nantes (France); M. Sjöström, Mid Sweden Univ. (Sweden)

$78631 \mathrm{U}$ Improved depth map estimation in stereo vision [7863-65]

H. Fradi, J.-L. Dugelay, EURECOM (France)

$78631 \mathrm{~V}$ Is visual fatigue changing the perceived depth accuracy on an autostereoscopic display? [7863-67]

M. Barkowsky, R. Cousseau, P. Le Callet, Institut de Recherche en Communications et

Cybernétique de Nantes, CNRS, Univ. de Nantes (France)

7863 IW Interlaced MVD format for free viewpoint video [7863-68]

S. Lee, S. Lee, J. Lee, H.-C. Wey, D.-S. Park, C.-Y. Kim, Samsung Electronics Co., Ltd. (Korea, Republic of)

$78631 \mathrm{X} \quad$ Visual discomfort prediction for stereo contents [7863-69]

S. He, T. Zhang, Technicolor (United States); D. Doyen, Technicolor S.A. (France) 
7863 IY Three-dimensional holographic display using active shutter for head mounted display application [7863-70]

H.-E. Kim, N. Kim, Chungbuk National Univ. (Korea, Republic of); H. Song, H.-S. Lee, Samsung Advanced Institute of Technology (Korea, Republic of); J.-H. Park, Chungbuk National Univ. (Korea, Republic of)

786312 Pixel-offset position detection using lens array for integral three-dimensional display [7863-71]

H. Sasaki, M. Kawakita, K. Masaoka, J. Arai, M. Okui, F. Okano, NHK Science \& Technology Research Labs. (Japan); Y. Haino, M. Yoshimura, M. Sato, JVC KENWOOD Holdings, Inc. (Japan)

786320 3D imaging for glasses-free multiview 3D displays [7863-72]

S. Gurbuz, M. Kawakita, National Institute of Information and Communications Technology (Japan); S. Yano, NHK Science \& Technical Research Labs. (Japan); S. Iwasawa, H. Ando, National Institute of Information and Communications Technology (Japan)

786321 Reduction of image blurring in an autostereoscopic multilayer liquid crystal display [7863-73]

H. Gotoda, National Institute of Informatics (Japan)

786322 A new volumetric 3D display using multi-varifocal lens and high-speed 2D display [7863-74] T. Sonoda, H. Yamamoto, S. Suyama, Univ. of Tokushima (Japan)

786324 Use of camera drive in stereoscopic display of learning contents of introductory physics [7863-76]

S. Matsuura, Tokyo Gakugei Univ. (Japan)

786326 DWT-based stereoscopic image watermarking [7863-78]

A. Chammem, Télécom SudParis (France) and Univ. Pierre et Marie Curie (France); M. Mitrea, Télécom SudParis (France); F. Prêteux, MINES ParisTech (France)

786327 Development of a new HD multiview camera and processing system [7863-79] C. Park, J. Lee, J. Kang, K. Lee, Korean Broadcasting System (Korea, Republic of)

786328 Multiview video codec based on KTA techniques [7863-80]

J. Seo, D. Kim, S. Ryu, K. Sohn, Yonsei Univ. (Korea, Republic of)

786329 On-screen-display (OSD) menu detection for proper stereo content reproduction for 3D TV [7863-81]

E. V. Tolstaya, V. V. Bucha, M. N. Rychagov, Samsung Electronics Co., Ltd. (Russian Federation)

$78632 \mathrm{~B}$ Analysis of scene distortions in stereoscopic images due to the variation of the ideal viewing conditions [7863-83]

A. Viale, D. Villa, Univ. degli Studi di Milano (Italy)

7863 2C Analysis of resolution limitation of a glasses-free tabletop 3D display [7863-84]

D. Moldovan, S. Yoshida, M. Kawakita, H. Ando, National Institute of Information and Communications Technology (Japan) 
7863 2D Image quality of up-converted 2D video from frame-compatible 3D video [7863-85]

F. Speranza, W. J. Tam, C. Vázquez, R. Renaud, P. Blanchfield, Communications Research Ctr. Canada (Canada)

$78632 \mathrm{E} \quad$ System crosstalk measurement of a time-sequential 3D display using ideal shutter glasses [7863-86]

F.-H. Chen, K.-C. Huang, L.-C. Lin, Y.-H. Chou, K. Lee, Industrial Technology Research Institute (Taiwan)

$78632 \mathrm{~F} \quad$ Guidance for horizontal image translation (HIT) of high definition stereoscopic video production [7863-87]

D. K. Broberg, Cable Television Labs., Inc. (United States)

Author Index 


\title{
Conference Committee
}

\author{
Symposium Chair \\ Sabine E. Süsstrunk, École Polytechnique Fédérale de Lausanne \\ (Switzerland) \\ Symposium Cochair
}

Majid Rabbani, Eastman Kodak Company (United States)

Conference Chairs

Andrew J. Woods, Curtin University (Australia)

Nicolas S. Holliman, Durham University (United Kingdom)

Neil A. Dodgson, University of Cambridge (United Kingdom)

Founding Chair

John O. Merritt, The Merritt Group (United States)

Program Committee

Gregg E. Favalora, Optics for Hire (United States)

Hideki Kakeya, University of Tsukuba (Japan)

Takashi Kawai, Waseda University (Japan)

Janusz Konrad, Boston University (United States)

Vivian K. Walworth, StereoJet, Inc. (United States)

Chris Ward, Lightspeed Design, Inc. (United States)

Michael A. Weissman, TrueVision Systems, Inc. (United States)

Samuel Zhou, IMAX Corporation (Canada)

\section{Session Chairs}

1 Visual Comfort and Quality

John O. Merritt, The Merritt Group (United States)

2 Combining Depth Cues

Vivian K. Walworth, StereoJet, Inc. (United States)

3 Keynote Presentation I

Nicolas S. Holliman, Durham University (United Kingdom) 
$4 \quad$ View Synthesis

Nicolas S. Holliman, Durham University (United Kingdom)

$5 \quad$ Multiview Systems

Neil A. Dodgson, University of Cambridge (United Kingdom)

$6 \quad$ Applications of Stereoscopic Displays

Chris Ward, Lightspeed Design, Inc. (United States)

$7 \quad$ Stereoscopic Display Developments

Michael A. Weissman, TrueVision Systems, Inc. (United States)

8 Evaluating the Quality of the Stereoscopic Experience I: Joint Session with Conference 7865

Andrew J. Woods, Curtin University (Australia)

9 Evaluating the Quality of the Stereoscopic Experience II: Joint Session with Conference 7865

Eli Peli, Schepens Eye Research Institute (United States)

10 Autostereoscopic Displays I

Gregg E. Favalora, Optics for Hire (United States)

11 Autostereoscopic Displays II

Vivian K. Walworth, StereoJet, Inc. (United States)

12 Keynote Presentation II

Neil A. Dodgson, University of Cambridge (United Kingdom)

13 Crosstalk in Stereoscopic Displays

Takashi Kawai, Waseda University (Japan)

14 3D Perception and Interaction

Hideki Kakeya, University of Tsukuba (Japan)

153 3D Content

Nicolas S. Holliman, Durham University (United Kingdom)

16 Stereoscopic Production and Playback

Samuel Zhou, IMAX Corporation (Canada)

Interactive Paper Session

Neil A. Dodgson, University of Cambridge (United Kingdom)

Andrew J. Woods, Curtin University (Australia) 


\section{Introduction}

For a twenty-second year, SD\&A was the premier venue for the dissemination of research into stereoscopic displays and their applications. SD\&A attracts key players in the field - stereoscopic experts from industry and academia were on our two panels, presenting the two keynote presentations, speakers of the technical presentations, and in the audience. The conference had an excellent technical program covering a wide range of stereoscopic topics. This year we were able to accept a little under half of the submitted papers for oral presentation, with an additional 37 papers accepted as posters.

This proceedings volume contains the technical papers in support of the presentations and posters given at the conference. This introduction gives an overview of the conference - a reminder for those who attended and an insight into what happened for those who were unable to attend.

The SD\&A conference was held 24-27 January 2011 as part of the 2011 IS\&T/SPIE Electronic Imaging: Science and Technology Symposium, at the Hyatt Regency San Francisco Airport Hotel, next to San Francisco Airport, in Burlingame, California, USA. This year's conference grew dramatically: There were $50 \%$ more attendees than last year, making it the best attended since the series began. Several of this year's sessions had over 200 people in the room, listening to presentations on a wide range of stereoscopic topics.

The first day had technical sessions on visual comfort and quality, combining depth cues, view synthesis, and multiview systems. There was our first keynote, the two-hour 3D theatre, and our conference banquet.

The first Keynote Presentation was given by Dr. Michael Robinson, Chief Scientist at RealD. He gave an excellent summary of the current state of stereoscopic 3D, in both cinema and television.

The two-hour 3D Theatre Session (chaired by Andrew Woods and Chris Ward) is a regular event that showcases 3D content from around the world. This was the most popular session of the conference, with over 300 attendees. This year, we screened the following pieces (or segments thereof) on the 5.6 meter (18 foot) diagonal stereoscopic projection screen:

\section{Competition Category}

- "Stereoikkuna" by Riku Naskali (Finland)

- "Hong Kong - Potential Unlimited" by Digital Magic (Hong Kong)

- "Ztring Theory" by Karl Bryhn and Jo Eldøen, Chiptoons (Norway)

- "Go Kia" by Dzignlight (United States)

- "The Girl Who Had No Fear" by John Hart (United States) 
- "Gloria (The Death of Me)" by Andrew Murchie, Enhanced Dimensions (United Kingdom)

- "My Best Stuff!" by Nat Bartholomew, Spinteck (United States)

- "Plasticity 3D" by Ryan Suits, Atomic Cheesecake Productions (United States)

- "Mercedes-Benz 3D 2010" by Lightspeed Design, Inc. (United States)

- "The Army Learning Concept 2015" by Digital Revolution Studios (United States)

- "Smart Action 3D" by Korean Broadcast Service (South Korea)

- "Stereo Timelapse" by Takashi Sekitani, STEREOeYe (Japan)

- "White Knuckles" by OK Go (United States)

- "Experiments in Stereoscopic Imaging" by Volker Kuchelmeister, UNSW iCinema Centre (Australia)

- "The Solo Adventures 3D" by The Digital Animation and Visual Effects School (United States)

- "Jack Daniels whisky company" by GALI-3D, Arnold Prague (Czech Republic)

- "Highly Strung" by Buzzbomb Media (Australia)

- "Holy Moly" by Passmore Lab (United States)

- "Microworlds" by Passmore Lab (United States)

- "3D Safari: Africa" by Digital Revolution Studios (United States)

- "Coming Home" by Rehela Jagric (Slovenia)

- "Citrullus Lanatus" by Argyris Theos (Greece)

- "3D MOOD Aquarium" by Lightspeed Design, Inc. (United States)

- "Spinteck 3D Shorts" by Nat Bartholomew, Spinteck (United States)

- "Dead Boring 3D" by Dave Edwardz, AFTRS (Australia)

- "Waiting for the End, Linkin Park" by Passmore Lab (United States)

- "Fractal Odyssey" by John Hart and Jerry Oldaker (United States)

\section{Demonstration Category}

(N.B.: items in the Demonstration Category were not judged for the Best of Show or Honorable Mention awards.)

- "Go Ahead!" by U-Staff (Japan)

- "Invincible Tiger - The Legend of Han Tao" by Blitz Games Studios (United Kingdom)

- "21st Century 3D Demo Reel" by 21st Century 3D (United States)

- " "Keitai Deka - Zenigata Yui" by BS-TBS Inc. (Japan)

- "2009 Stereo Clips" by Enxebre (Spain)

- "Une Nuit Au Cirque 3D" by Olivier Kauffer and Fabien Remblier (France)

- "Gnomeo and Juliet (trailer)" by Walt Disney Studios (United States)

- "Hidden 3D (Opening Title Sequence)" by Dzignlight Studios (United States)

- "Immersive PC Games with NVIDIA 3D Vision" by various games companies

- "Maker Faire" by Stone Circle Productions (United States)

- "3D AFL Grand Final (Australian Rules Football)" by Seven Network (Australia) and 3Ality Digital (United States)

- "StreetDance 3D (trailer)" by Paradise FX (United States)

- "Tekkonkinkreet - 3D digest" by Tekkonkinkreet Program Committee (Japan)

- "Garo Red Requiem 3D" by Keita Amemiya (Japan). 
In recognition of the high quality of material shown at the 3D Theatre, we offered three "Best of Show" prizes for pieces entered into the Competition Category. The judges were Dr. Samuel Zhou, Director of Image Technology at IMAX Corporation, Canada, and Bernard Mendiburu, author of 3D Movie Making: Stereoscopic Digital Cinema from Script to Screen. The winners and honorable mentions in the three categories were:

Best of Show - Live Action:

"White Knuckles 3D" by OK Go (United States)

Honorable Mention - Live Action:

"Stereo Timelapse" by Takashi Sekitani, StereoEyE (Japan)

Best of Show - Computer Graphics:

"Fractal Odyssey" by John Hart and Jerry Oldaker (United States)

Honorable Mention - Computer Graphics:

"Holy Moly" by Passmore Labs (United States)

Best of Show - Visual Effects:

"Dead Boring" by Dave Edwardz, AFTRS (Australia)

Honorable Mention - Visual Effects:

"Experiments in Stereoscopic Imaging" by Volker Kuchelmeister, UNSW

iCinema Centre (Australia)

An illustrated listing of the content shown during this year's 3D Theatre session is available from the conference website:

\section{www.stereoscopic.org/3dcinema}

Many thanks to Dan Lawrence at Lightspeed Design who handled the data wrangling for the 3D Theatre session, and Stephan Keith who helped with the content specifications handling.

The evening concluded with our traditional conference dinner at a new venue: $\mathrm{El}$ Torito on the bay front near the conference hotel. Approximately 60 conference attendees mingled, talked, and ate in a relaxed atmosphere. We will do it again next year!

The second day of the SD\&A conference had technical sessions on applications and developments, a joint session with the HVEl conference (Human Vision and Electronic Imaging, Proc. SPIE Vol. 7865) on quality evaluation, the demonstration session, and the poster session. The full papers from both the technical sessions and the poster session are all contained in this volume - except for two of the 
papers from the joint session which will appear in Proceedings of SPIE Volume 7865:

- "Examination of 3D visual attention in stereoscopic video content," Huynh-Thu Quan, Luca Schiatti, Technicolor (France) (7865-20), and

- "Quantifying how the combination of blur and disparity affects the perceived depth," Junle Wang, Marcus Barkowsky, Vincent Ricordel, Patrick Le Callet, Univ. de Nantes (France) (7865-21).

The first discussion forum considered 3DTV dangers: truth or fiction. Lenny Lipton chaired a panel of experts: Marty Banks (UC Berkeley), Eli Peli (Harvard University), Christopher Riemann (Cincinnati Eye Institute), and Pete Ludé (Sony Electronics). They were skeptical of the extreme warnings that have recently been released by consumer electronics companies. Lenny, in particular, pointed out that, in 20 years of selling active glasses, he had never had a single complaint about eye strain. However, the panel also pointed out that the human visual system never stops adjusting to its environment and that there are many things we do not know. There was a plea for display engineers and human vision scientists to partner in conducting research.

The final event of the day was the ever-popular Demonstration Session, which has run every year since 1990. Since 2006, this has been a symposium-wide event, open to demonstrators from all of the Electronic Imaging conferences. It was pleasing to see a wide range of demonstrations and to see a large audience actively engaging with the various displays and vendors. The energy in the demonstration session was astounding and many demonstrators were still going strong after two and a half hours.

This year the following 3D hardware and 3D software products were on show at the demonstration session:

- JVC (Rod Sterling) demonstrated a pre-release version of the new GS-TD1 Full-HD stereoscopic camcorder which is scheduled for release in March.

- $\quad$ NVIDIA (Dave Cook and Michael McSorley) showed a 3D Vision Surround system consisting of the 3D Vision product running across three screens (Alienware AW2310 120HZ 3D LCD monitors) viewed with 3D Vision active shutter glasses and running the game Mafia 2. Graphics cards used were two GeForce GTX580s.

- DDD (Julien Flack and his team) demonstrated their TriDef 3D game and 3D video software driving a large screen 3D TV and two 3D notebook computers all viewed with active shutter glasses - specifically:

- an HP Envy 17" 3D notebook running EA's Need for Speed Hot Pursuit in 3D,

- an Acer 5738DG 3D notebook demonstrating TriDef 3D's real-time 2D to 3D conversion process for HD video, and

- a Samsung 3D TV driven by a standard shuttle PC with an AMD Radeon 6000 GPU connecting via HDMI 1.4 and using TriDef 3D's game drivers to run EA's Medal of Honor in 3D. 
- Ainsworth \& Partners (Richard Ainsworth assisted by Dan Sandin) showed their stereoscopic panoramic photography system: two cameras on a motorized mount, with associated software.

- HumanEyes (Assaf Zomet and Shmuel Peleg) demonstrated their multiview cross-talk reduction mechanism on both an autostereoscopic monitor and on lenticular 3D prints.

- Centre for Vision Research, York University, Toronto (Inna Tsirlin \& Laurie Wilcox) showed the experimental stimuli for their work on evaluating the effect of cross-talk (as presented in SPIE paper 7863-37).

- Ronald S. Karpf demonstrated a prototype of their continuously adjustable Pulfrich spectacles.

- Accurex Measurement showed their Stereoscan 3D scanning hardware and software.

- Volfoni demonstrated their ActiveEyes glasses that can work with (almost) any active or passive circularly polarized display.

- The University of Tsukuba (Hideki Kakeya and his team) had two demonstrations: both variations on integral imaging, using beam splitters and multiple displays to produce three-dimensional multi-view images.

- The Tokyo University of Agriculture and Technology (Yasuhiro Takaki and Junya Nakamura) showed a super multi-view display with viewing zones only $2.6 \mathrm{~mm}$ wide. Each eye had eight abutting viewing zones, so head movement was restricted. Zones this narrow allowed some people to converge and accommodate at the same depth, other than the screen depth.

- Lightspeed Design (Chris Ward) demonstrated their DepthQ polarization modulator in operation with their latest DepthQ HD projector.

- 3M Company (Michael Sykora, Vincent King and Glenn Casner) showed their new two-view autostereoscopic display, which is used in a recently released commercial device.

- ELDIM (Pierre Boher) provided literature on their system for performance characterization of autostereoscopic displays.

A prize was awarded for the best demonstration at the session. The judging panel was chaired by Prof. Neil Dodgson. The prize was awarded to HumanEyes, with honorable mentions to York University and the Tokyo University of Agriculture and Technology.

An extensive photo montage and listing of the demonstration session and exhibits from this year's SD\&A conference will be available on the conference website:

\section{www.stereoscopic.org}

The third day of the SD\&A conference had technical sessions on autostereoscopic displays, crosstalk, 3D perception and interaction. There was the second keynote and the symposium reception with a 3D gaming demonstration. 
The second Keynote Presentation was given by Prof. Ramesh Raskar (MIT Media Lab). He inspired the audience with his talk of 4D, 5D, 6D and 8D displays. He gave a broad sweep across a range of ideas coming out of his laboratory, leaving the audience with many new ideas. Further information is available from raskar.info.

The Electronic Imaging Symposium Reception on Wednesday evening was a great way to chat and relax with colleagues. As an added attraction, two 3D gaming demonstration systems were setup during the reception to add a bit of fun to the evening. Each system consisted of a new JVC RS40 LCOS Full-HD 3D projector, each driven by a Playstation 3 console running in 3D mode, projecting onto a large projection screen and viewed using active shutter glasses. The PS3 3D games being shown were "Tron: Evolution" on the first system and "Avatar: The Game" on the second system. Many thanks to Rod Sterling and Steve Inove from JVC and Stephan Keith for supporting this event with equipment and helping with setup. Many attendees enjoyed playing these systems in 3D.

For the first time, SD\&A went into a fourth day. There were technical sessions on 3D content, stereoscopic production and playback, and the second of our discussion forums.

The second discussion forum considered screen size factors. The panel comprised Bernard Mendiburu (Chair), David Broberg (CableLabs), John Merrit (The Merritt Group), Jukka Häkkinen (Aalto University) and Frédéric Devernay (INRIA).

All sessions at this year's SD\&A conference were video recorded thanks to River Valley Technologies. Editing is underway and the content will be available online very soon.

A final prize was offered at the conference for the best use of the stereoscopic projection tools during the technical presentations. The winner, chosen by the SD\&A conference chairs, was:

- Christopher Riemann (Cincinnati Eye Institute \& MedNet Technologies), "Machine vision and vitrectomy: three-dimensional high definition video for surgical visualization in vitreoretinal surgery."

The prizes this year were copies of Stereoscopic Displays and Applications 19902009: A Complete 20-Year Retrospective and The Engineering Reality of Virtual Reality 1994-2009 (Selected SPIE/IS\&T papers on DVD-ROM), published by SPIE in 2010, and copies of Bernard Mendiburu's book 3D Movie Making: Stereoscopic Digital Cinema from Script to Screen, published in 2009 by Elsevier. Congratulations to all our prize-winners in the cinema, demonstration, and presentation awards. 
Many individuals and companies contributed in various ways to the success of this year's SD\&A conference:

- The major sponsors of this year's conference were IMAX Corporation (Mississauga, Ontario, Canada) and DepthQ Stereoscopic (Bellevue, Washington). Conference sponsorship is a valuable way for companies to support the running of the conference and to gain marketing exposure. IMAX and DepthQ are both key players in the stereoscopic industry, and we thank them for their support.

- We also appreciate the support of this year's stereoscopic projection sponsors: Christie Digital (Cypress, California), Visitech 3D (Los Angeles, California) and STRONG / MDI Screen Systems (Joliette, Quebec, Canada).

The ability to present high-quality large-screen stereoscopic images and video at the conference is vital to the conference's success. This year we had a Christie Digital Mirage WU7K-M projector (1920×1200 resolution, 16:9 aspect ratio, 3 chip DLP, 6300 lumens, provided by Christie Digital) projecting onto a $4.9 \times 2.7$ meter screen (provided by STRONG / MDI Screen Systems and setup by Visitech 3D), outputting frame-sequential circularly-polarized 3D (at $120 \mathrm{~Hz}$ ) by way of a DepthQ active polarization modulator (provided by DepthQ Stereoscopic). The system was driven by a DepthQ stereoscopic media server for playback of all of the stereoscopic video content shown during the 3D Theatre. Many thanks for a for a job done extremely well go to: Chris Ward and Dan Lawrence from DepthQ Stereoscopic; Wayne Bickley from Christie Digital; Brad Nelson from Visitech 3D, François Barrette from Strong / MDI Screen Systems; and Adrian Romero and staff from Spectrum Audio Visual. The AV setup was project managed by Diana Gonzalez from IS\&T and Andrew Woods from Curtin University.

- We thank our media sponsors who helped promote the conference: Veritas et Visus and Dimension 3.

- We very much appreciate the dedicated support of Stephan R. Keith (SRK Graphics Research), who had a multi-tasked role at this conference, helping support the AV needs of all of our presenters.

- We are grateful to all of the providers of 3D content for the 3D Theatre session for allowing their content to be shown to the conference audience.

- Thanks to the demonstration session presenters for bringing equipment to show. A lot of equipment traveled from overseas, making the contribution to the meeting particularly worthy of additional praise.

- The conference committee plays an important role throughout the year, ensuring the correct technical direction of the meeting. Sincere thanks go to our founding chair, John Merritt, and our committee, Gregg Favalora, Hideki Kakeya, Takashi Kawai, Janusz Konrad, Vivian Walworth, Chris Ward, Michael Weissman, and Samuel Zhou.

- Thanks also to the staff at IS\&T and SPIE, who were instrumental in helping to organize the meeting. 
- Most importantly, we thank the conference authors and attendees, who ultimately made this meeting such a successful event. Thanks especially to those who travel a long way to join us each year.

Conference activities do not stop at the end of the January meeting. The SD\&A conference website and Linked-In group provide focuses for conference activities during the time between conferences. We will soon be actively seeking abstracts for the 2012 conference, with a deadline in June 2011 - see the website for details and deadlines. You can join the conference mailing list to receive conference announcements: visit the SD\&A conference website for details. The website has an extensive collection of photographs highlighting the activities of past conferences. In addition the website hosts the stereoscopic virtual library, which contains several historically important books that have been digitized, in full, into PDF format, and are available for free download. We have an active discussion group on the business networking site Linkedln:

\section{www.linkedin.com/groups?gid $=1945944$}

Visit the conference website to gain an understanding of the past, present, and future of stereoscopic imaging and, most of all, think now about submitting a paper or attending next year's conference. The Stereoscopic Displays and Applications conference website is at:

\section{www.stereoscopic.org}

Next year, the 23rd conference will be held for three (or possibly four) days in the period 23-26 January 2012, at the Hyatt Regency San Francisco Airport Hotel, as part of the 2012 IS\&T/SPIE Electronic Imaging: Science \& Technology Symposium. The hotel is twenty minutes from central San Francisco by public transport. It is very close to the international airport and there will be free shuttle buses running from San Francisco International Airport to the conference venue. Parking is easy for local attendees. The conference will be in the same week as Photonics West (which will be held in central San Francisco) with all SD\&A attendees automatically being registered for access for the Photonics West exhibition.

The 2012 SD\&A conference will continue a tradition of presenting and demonstrating the latest technologies relevant to stereoscopic displays and applications. Please consider attending, presenting, or demonstrating at the 2012 Stereoscopic Displays and Applications conference. We hope to see you there!

Andrew J. Woods
Nicolas S. Holliman
Neil A. Dodgson 
Stereoscopic Displays and Applications XXII

(2011)

\section{Official Conference Sponsors}

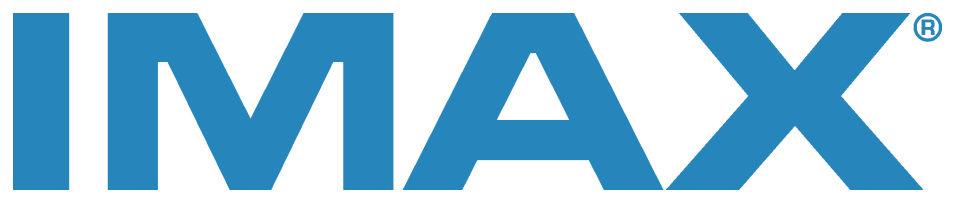

\section{Projection Sponsors}

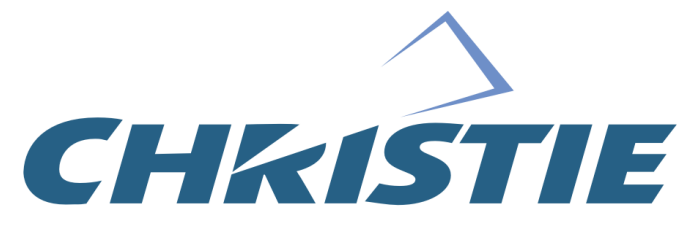

VISITECH 3D

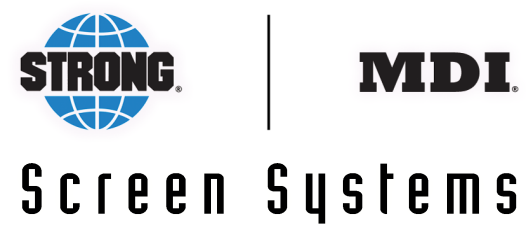


Downloaded From: https://www.spiedigitallibrary.org/conference-proceedings-of-spie on 26 Apr 2023

Terms of Use: https://www.spiedigitallibrary.org/terms-of-use 